\title{
THE CORRELATIONS BETWEEN RELATIVES FOR A SEX-LINKED CHARACTER UNDER INBREEDING
}

\author{
V. T. KORDE * \\ Indian Statistical Institute, Calcutta
}

Received 19.X.59

\section{INTRODUCTION}

THE method of analysing quantitative data by obtaining theoretical values for the correlations between relatives was developed by Fisher (I9I8). He derived expressions for correlations for different relationships under random mating. In recent years, the problem of correlations between relatives under inbreeding has aroused much interest in the field of quantitative inheritance as is evidenced by the papers of Horner (I956) and Kempthorne (I955). The particular form of inbreeding considered by Horner was the alternate parent-offspring mating and Kempthorne worked with the full-sib mating system. But in both these papers, the case of autosomal genes alone is dealt with, although under inbreeding, the progress towards homozygosis for a sex-linked character has long been studied by Fisher (I949) and Haldane (1937, I955).

In this paper we have considered the case of a sex-linked character under full-sib mating system. The expressions for covariances between the four parent-offspring pairs, and the three full-sib pairs are derived. Some general expressions for the correlations between an individual and his/her offspring of $k^{\text {th }}$ degree are derived under the assumption of no dominance, and the limiting values of these general expressions are discussed.

\section{DEFINITIONS AND NOTATIONS}

We consider here the case of one locus with two alleles, A and $a$. It is assumed that the female is homogametic, $\mathrm{XX}$, and the male is heterogametic, XY, with respect to the sex-chromosomes. The frequencies for the six different mating types in the $n^{\text {th }}$ generation with the offspring produced in the $(n+\mathrm{I})^{\text {th }}$ generation are given in table I below.

The frequencies in the $(n+\mathrm{I})^{\text {th }}$ generation are related to those in the $n^{\text {th }}$ generation by the relation

$$
\mathbf{L}^{(n+1)}=\mathrm{B} \mathrm{L}^{(n)}
$$

where $B$ is the matrix

$$
\mathrm{B}=\left(\begin{array}{llllll}
\text { I } & 0 & 0 & 0 & \frac{1}{4} & 0 \\
0 & I & 0 & 0 & 0 & \frac{1}{4} \\
0 & 0 & 0 & 0 & \frac{1}{4} & 0 \\
0 & 0 & 0 & 0 & 0 & \frac{1}{4} \\
0 & 0 & I & 0 & \frac{1}{4} & \frac{1}{4} \\
0 & 0 & 0 & I & \frac{1}{4} & \frac{1}{4}
\end{array}\right)
$$

* Present address : Section of Statistics, All-India Institute of Hygiene and Public Health, I I 0 Chittaranjan Avenue, Calcutta 12. 
and $\mathbf{L}^{(n)}$ is the column vector

$$
\mathbf{L}^{(n)}=\left(\begin{array}{c}
\mathrm{L}_{1}^{(n)} \\
\mathrm{L}_{2}^{(n)} \\
\mathrm{L}_{3}^{(n)} \\
\mathrm{L}_{4}^{(n)} \\
\mathrm{L}_{5}^{(n)} \\
\mathrm{L}_{6}^{(n)}
\end{array}\right)
$$

Such a matrix has already been considered by Fisher (I949) and Haldane (I 955).

TABLE I

\begin{tabular}{|c|c|c|c|c|c|c|c|}
\hline \multirow{3}{*}{ No. } & \multirow{3}{*}{ Mating type } & \multirow{3}{*}{$\begin{array}{l}\text { Frequency in the } \\
n^{\text {th }} \text { generation }\end{array}$} & \multicolumn{5}{|c|}{$\begin{array}{l}\text { Offspring produced in the } \\
(n+1)^{\text {th }} \text { generation }\end{array}$} \\
\hline & & & \multicolumn{2}{|c|}{ Male } & \multicolumn{3}{|c|}{ Female } \\
\hline & & & A & $a$ & AA & $\mathrm{A} a$ & $a a$ \\
\hline I & $\mathrm{A} \times \mathrm{AA}$ & $\mathrm{L}_{1}^{(n)}$ & I & $\cdots$ & I & $\ldots$ & ... \\
\hline 2 & $a \times a a$ & $\mathrm{~L}_{2}^{(n)}$ & $\cdots$ & I & $\cdots$ & $\ldots$ & I \\
\hline 3 & $a \times \mathrm{AA}$ & $\mathrm{L}_{3}^{(\bar{n})}$ & I & $\cdots$ & $\ldots$ & I & ... \\
\hline 4 & $\mathrm{~A} \times a a$ & $\mathrm{~L}_{4}^{(n)}$ & $\cdots$ & I & $\cdots$ & I & $\cdots$ \\
\hline 5 & $\mathrm{~A} \times \mathrm{A} a$ & $\mathrm{~L}_{5}^{(\bar{n})}$ & $\frac{1}{2}$ & $\frac{1}{2}$ & $\frac{1}{2}$ & $\frac{1}{2}$ & $\ldots$ \\
\hline 6 & $a \times \mathrm{A} a$ & $\mathrm{~L}_{6}^{(n)}$ & $\frac{1}{2}$ & $\frac{1}{2}$ & $\cdots$ & $\frac{1}{2}$ & $\frac{1}{2}$ \\
\hline
\end{tabular}

It is easily seen that the latent roots of (2.2) are $I, \frac{1}{2},-\frac{1}{2}, \epsilon, \epsilon^{\prime}$ and I, where $\epsilon$ and $\epsilon^{\prime}$ are the roots of the equation

$$
4 x^{2}-2 x-\mathrm{I}=0
$$

If initially the population was random mating and at equilibrium, i.e. the vector $\mathbf{L}^{(0)}$ is obtained by symbolically multiplying

$$
(p \mathrm{~A}+q a)\left(p^{2} \mathrm{AA}+2 p q \mathrm{~A} a+q^{2} a a\right)
$$

where $p$ is the frequency of the allele A, then following Fisher (1949), the genotypic array for the females in the $n^{\text {th }}$ generation can be written as

$$
\left\{p-p q\left(\mathrm{I}-\mathrm{F}_{n}\right)\right\} \mathrm{AA}+2 p q\left(\mathrm{I}-\mathrm{F}_{n}\right) \mathrm{A} a+\left\{q-p q\left(\mathrm{I}-\mathrm{F}_{n}\right)\right\} a a
$$

and that for the males being

$$
p \mathrm{~A}+q a
$$

for all $n$.

It may be verified that the $\mathrm{F}_{n}$ used in (2.6) is the same as that used by Kempthorne (1955) for an autosomal gene, the initial conditions remaining the same. A similar result is given by Haldane (I937). 
Let the genotypic values for the two sexes be coded as follows:

Sex

Female

\begin{tabular}{ccc} 
A $a$ & $\frac{y_{1}-x_{1}}{2}$ \\
Male $\cdot$ & $\begin{array}{c}\text { A } \\
a\end{array}$ & 0 \\
\hline & $\begin{array}{c}y_{2} \\
0\end{array}$
\end{tabular}

With these values, the means for the females and the males in the $n^{\text {th }}$ generation, denoted by $\mu_{n}$ and $\mu_{n}^{\prime}$ respectively are given by

$$
\begin{aligned}
& \mu_{n}=p y_{1}-p q x_{1}\left(\mathrm{I}-\mathrm{F}_{n}\right) \\
& \mu_{n}^{\prime}=p y_{2}
\end{aligned}
$$

and similarly the variances are given by

$$
\begin{aligned}
\mathrm{V}_{n}=\frac{\left(\mathrm{I}+\mathrm{F}_{n}\right)}{2} p q y_{1}^{2}+\frac{\left(\mathrm{I}-\mathrm{F}_{n}\right)}{2} p q x_{1}^{2}-\left(\mathrm{I}-\mathrm{F}_{n}\right)^{2} p^{2} q^{2} x_{1}^{2} \\
+\left(\mathrm{I}-\mathrm{F}_{n}\right) p q(p-q) x_{1} y_{1} \\
\mathrm{~V}_{n}=p q y_{2}^{2} .
\end{aligned}
$$

\section{PARENT OFFSPRING AND FULL-SIB COVARIANCES}

Let the parent belong to the $n^{\text {th }}$ generation and the offspring to the $(n+1)^{\text {th }}$ generation. Then, the expressions for the covariances for the four parent-offspring pairs are as given below:

(a) $\operatorname{Cov}$ (Father, son) $=\mathrm{F}_{n+1} p q y_{2}^{2}$

(b) $\operatorname{Cov}($ Mother, son $)=\frac{\left(\mathrm{I}+\mathrm{F}_{n}\right)}{2} p q y_{1} y_{2}+\frac{\left(\mathrm{I}-\mathrm{F}_{n}\right)}{2} p q(p-q) x_{1} y_{2}$

(c) $\operatorname{Cov}$ (Father, daughter) $=\frac{\left(\mathrm{I}+\mathrm{F}_{n+1}\right)}{2} p q y_{1} y_{2}$

$$
+\frac{\left(\mathrm{I}-\mathrm{F}_{n+1}\right)}{2} p q(p-q) x_{1} y_{2}
$$

(d) $\operatorname{Cov}$ (Mother, daughter) $=\mathrm{F}_{n+2} p q y_{1}^{2}+\frac{\left(\mathrm{I}-\mathrm{F}_{n}\right)}{4} p q x_{1}^{2}$

$$
\begin{aligned}
& -\left(\mathrm{I}-\mathrm{F}_{n}\right)\left(\mathrm{I}-\mathrm{F}_{n+1}\right) p^{2} q^{2} x_{1}^{2}-\left[\left(\frac{1}{2}\right)^{n}\right. \\
& \left.-\left(2-\mathrm{F}_{n}-\mathrm{F}_{n+1}\right)\right] \frac{p q(p-q)}{2} x_{1} y_{1}
\end{aligned}
$$

It may be verified that (3.4) is the same as the parent-offspring covariance for an autosomal gene as given by Kempthorne (1955). 
For full sibs in the $(n+1)^{\text {th }}$ generation, the covariances for the three full-sib pairs are as given below:

(e) Cov (Full brothers) $=\frac{\left(\mathrm{I}-\mathrm{F}_{n}\right)}{2} p q y_{2}^{2}$

(f) Cov (Brothers, sisters) $=\mathrm{F}_{n+2} p q y_{1} y_{2}-\left[\left(\frac{1}{2}\right)^{n+1}\right.$

$$
\left.-\left(\mathrm{I}-\mathrm{F}_{n+1}\right)\right] \frac{p q(p-q)}{2} x_{1} y_{2}
$$

(g) Cov (Full sisters) $=\mathrm{F}_{n+3} p q y_{1}^{2}-\left(\mathrm{I}-\mathrm{F}_{n^{+} 3}\right) p q x_{1}^{2}$

$$
\begin{aligned}
& -\left[\left(\frac{1}{2}\right)^{n}-4\left(\mathrm{I}-\mathrm{F}_{n+1}\right)\right] \frac{p q(p-q)}{4} x_{1} y_{1} \\
& +\left(\mathrm{I}-\mathrm{F}_{n+1}\right)\left[\mathrm{I}-p q\left(\mathrm{I}-\mathrm{F}_{n+1}\right)\right] p q x_{1}^{2}
\end{aligned}
$$

When $x_{1}=0$, i.e. there is no dominance, the correlation coefficients are as follows:

$$
\begin{aligned}
& \text { (a) }{ }_{f} \rho_{s}=\mathrm{F}_{n+1} \\
& \text { (b) }{ }_{m} \rho_{s}=\left(\frac{\mathrm{I}+\mathrm{F}_{n}}{2}\right)^{\frac{1}{2}} \\
& \text { (c) }{ }_{f} \rho_{d}=\left(\frac{\mathrm{I}+\mathrm{F}_{n+1}}{2}\right)^{\frac{1}{2}} \\
& \text { (d) }{ }_{m} \rho_{d}=2 \mathrm{~F}_{n+2}\left(\mathrm{I}+\mathrm{F}_{n}\right)^{-\frac{1}{2}}\left(\mathrm{I}+\mathrm{F}_{n+1}\right)^{-\frac{1}{2}} \\
& \text { (e) } \rho_{b-b}=\frac{\mathrm{I}+\mathrm{F}_{n}}{2} \\
& \text { (f) } \rho_{s i b}=2 \mathrm{~F}_{n+2}\left\{2\left(\mathrm{I}+\mathrm{F}_{n+1}\right)\right\}^{-\frac{1}{2}} \\
& \text { (g) } \rho_{s i s-s i s}=2 \mathrm{~F}_{n+3}\left(\mathrm{I}+\mathrm{F}_{n+1}\right)^{-1}
\end{aligned}
$$

where ${ }_{f} \rho_{s}=$ Corr. coeff. between father in the $n^{\text {th }}$ generation and son in the $(n+\mathrm{I})^{\text {th }}$ generation;

and $\rho_{b-b}=$ Corr. coeff. between two full brothers in the $(n+1)^{\text {th }}$ generation and so on. sions,

The following inequalities are obtained from the above expres-

I. $\rho_{s i b}<{ }_{m} \rho_{d}$

2. ${ }_{f} \rho_{d}>{ }_{m} \rho_{s}>\rho_{b-b}>{ }_{f} \rho_{s}$.

\section{GENERAL EXPRESSIONS}

In this case, it is possible to find the expressions for correlation coefficients between parents in the $n^{\text {th }}$ generation and the $k^{\text {th }}$ degree offspring. We use the following notation:

$$
\begin{aligned}
& \mathrm{X}_{n}=\text { Female parent in the } n^{\text {th }} \text { generation } \\
& \mathrm{Y}_{n}=\text { Male parent in the } n^{\text {th }} \text { generation } \\
& \mathrm{S}_{n+k}=\text { Male offspring of the } k^{\text {th }} \text { degree in the }(n+k)^{\text {th }} \text { generation } \\
& \mathrm{D}_{n+k}=\text { Female offspring of the } k^{\text {th }} \text { degree in the }(n+k)^{\text {th }} \text { genera- } \\
& \quad \text { tion. }
\end{aligned}
$$


We find the correlation coefficients under the assumption of no dominance.

$$
\text { (i) Corr. }\left(\mathrm{Y}_{n}, \mathrm{~S}_{n+k}\right)
$$

We first find the covariance. For this, it is necessary to find the probability that both $\mathrm{Y}_{n}$ and $\mathrm{S}_{n+k}$ are of genotype A.

Now, as $\mathrm{Y}_{n}$ is of the type $\mathrm{A}$, we need only consider the matings of the type I, 4 and 5 of table I. Also, the probability of getting a male offspring of the type A for the six different mating types can be represented by the vector ( 1 o I $\circ \frac{1}{2} \frac{1}{2}$ ). Thus the probability that both $\mathrm{Y}_{n}$ and $\mathrm{S}_{n+k}$ are $\mathrm{A}$ can be written as:

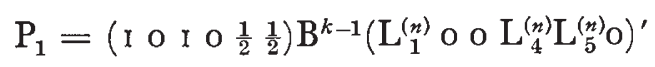

where $\mathrm{B}$ is the matrix (2.2).

Thus

$$
\operatorname{Cov}\left(\mathrm{Y}_{n}, \mathrm{~S}_{n+k}\right)=\mathrm{P}_{1} y_{2}^{2}-p^{2} y_{2}^{2}
$$

It may be noted that this as well as the subsequent results hold for $k=\mathrm{I}$ with $\mathrm{B}^{k-1}=\mathrm{B}^{0}=\mathrm{I}, \mathrm{I}$ being the unit matrix.

The correlation coefficients which can now be easily found for different values of $k$ are given in table 2 below:

TABLE 2

\begin{tabular}{|c|c|c|c|c|c|}
\hline $\mathrm{K}$ & $\mathrm{I}$ & 2 & 3 & 4 & 5 \\
\hline${ }_{n} \rho_{k}$ & $\mathrm{~F}_{n+1}$ & $\frac{\mathrm{I}+\mathrm{F}_{n+1}}{2}$ & $\frac{\mathrm{I}+3 \mathrm{~F}_{n+1}}{4}$ & $\frac{3+5 \mathrm{~F}_{n+1}}{8}$ & $\frac{5+\mathrm{II} \mathrm{F} \mathrm{F}_{n+1}}{\mathrm{I} 6}$ \\
\hline
\end{tabular}

It may be noted that ${ }_{n} \rho_{k}$ satisfies the difference equation

$$
{ }_{n} \rho_{k+2}=\frac{1}{2}\left[{ }_{n} \rho_{k}+{ }_{n} \rho_{k+1}\right]
$$

with

$$
\begin{aligned}
& { }_{n} \rho_{1}=\mathrm{F}_{n+1} \\
& { }_{n} \rho_{2}=\frac{\mathrm{I}+\mathrm{F}_{n+1}}{2}
\end{aligned}
$$

The general solution of (4.1.3) can be written as

$$
{ }_{n} \rho_{k}=\frac{\mathrm{I}+2 \mathrm{~F}_{n+1}}{3}+\left(-\frac{1}{2}\right)^{k} \frac{2\left(\mathrm{I}-\mathrm{F}_{n+1}\right)}{3}
$$

For sufficiently large value of $k$, the second term in (4.I.4) may be neglected and we get

$$
{ }_{n} \rho_{\infty}=\frac{\mathrm{I}+2 \mathrm{~F}_{n+1}}{3}
$$

$2 \mathrm{C}$ 
(ii) Corr. $\left(\mathrm{Y}_{n}, \mathrm{D}_{n+k}\right)$

Let

$$
\left.\begin{array}{l}
\mathrm{P}_{11}^{\prime}=\operatorname{Prob}\left[\mathrm{Y}_{n}=\mathrm{A} ; \mathrm{D}_{n+k}=\mathrm{AA}\right] \\
\mathrm{P}_{12}^{\prime}=\operatorname{Prob}\left[\mathrm{Y}_{n}=\mathrm{A} ; \mathrm{D}_{n+k}=\mathrm{A} a\right]
\end{array}\right\}
$$

Then we have

Hence

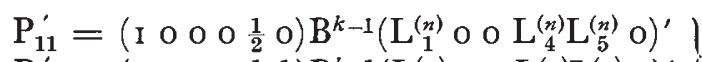

$$
\begin{aligned}
& \mathrm{P}_{12}^{\prime}=\left(\begin{array}{llll}
\text { O O I I } & \left.\frac{1}{2} \frac{1}{2}\right) \mathrm{B}^{k-1}\left(\mathrm{~L}_{1}^{(n)} \text { o o o } \mathrm{L}_{5}^{(n)} \mathrm{L}_{4}^{(n)} \text { o }\right)^{\prime}
\end{array}\right)
\end{aligned}
$$

Hence

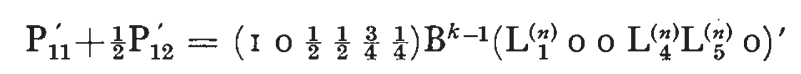

$$
\operatorname{Cov}\left(\mathrm{Y}_{n}, \mathrm{D}_{n+k}\right)=\left[\mathrm{P}_{11}^{\prime}+\frac{1}{2} \mathrm{P}_{12}^{\prime}\right] y_{1} y_{2}-p^{2} y_{1} y_{2}
$$

The correlation coefficients for different values of $k$ are given below in table 3 .

TABLE 3

\begin{tabular}{|c|c|c|c|}
\hline $\mathrm{K}$ & $\mathrm{I}$ & 2 & 3 \\
\hline${ }_{n}^{\prime} \rho_{k}^{\prime}$ & $\left(\frac{\mathrm{I}+\mathrm{F}_{n+1}}{2}\right)^{\frac{1}{2}}$ & $\frac{\mathrm{I}+3 \mathrm{~F}_{n+1} \times\left(\frac{\mathrm{I}+\mathrm{F}_{n+2}}{2}\right)^{-\frac{1}{2}}}{\frac{3}{2}}$ & $\frac{3+5 \mathrm{~F}_{n+1} \times\left(\frac{\mathrm{I}+\mathrm{F}_{n+3}}{2}\right)^{-\frac{1}{2}}}{8}$ \\
\hline
\end{tabular}

In general, we have

$$
{ }_{n} \rho_{k}^{\prime}=\left({ }_{n} \rho_{k+1}\right)\left(\frac{\mathrm{I}+\mathrm{F}_{n+k}}{2}\right)^{-\frac{1}{2}}
$$

where ${ }_{n} \rho_{k+1}$ is given by (4.1.4) with $k$ replaced by $k+\mathrm{I}$. Thus, for large $k$,

as $\mathrm{F}_{n+k} \rightarrow \mathrm{I}$.

$$
\begin{aligned}
{ }_{n} \rho_{k}^{\prime} & \simeq_{n} \rho_{k+1} \\
& \simeq{ }_{n} \rho_{k}
\end{aligned}
$$

(iii) Corr. $\left(\mathrm{X}_{n}, \mathrm{~S}_{n+k}\right)$

Let

Then,

$$
\left.\begin{array}{l}
\mathrm{Q}_{11}=\operatorname{Prob}\left[\mathrm{X}_{n}=\mathrm{AA} ; \mathrm{S}_{n+k}=\mathrm{A}\right] \\
\mathrm{Q}_{12}=\operatorname{Prob}\left[\mathrm{X}_{n}=\mathrm{A} a ; \mathrm{S}_{n+k}=\mathrm{A}\right]
\end{array}\right\}
$$

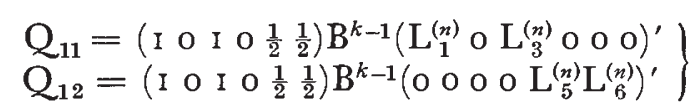

Hence

$$
Q_{11}+\frac{1}{2} Q_{12}=\left(\begin{array}{lllll}
\text { I } & \text { I I } & \text { o } & \frac{1}{2} & \frac{1}{2}
\end{array}\right) B^{k-1}\left(\mathrm{~L}_{1}^{(n)} \circ L_{3}^{(n)} \circ \frac{L_{5}^{(n)}}{2} \frac{L_{6}^{(n)}}{2}\right)^{\prime}
$$


Hence,

$$
\operatorname{Cov}\left(\mathrm{X}_{n}, \mathrm{~S}_{n+k}\right)=\left[\mathrm{Q}_{11}+\frac{1}{2} \mathrm{Q}_{12}\right] y_{1} y_{2}-p^{2} y_{1} y_{2}
$$

Table 4 gives the correlation coefficients for different values of $k$.

TABLE 4

\begin{tabular}{|c|c|c|c|c|}
\hline $\mathrm{K}$ & $\mathrm{I}$ & 2 & 3 & 4 \\
\hline${ }_{n} \eta_{k} \mathrm{x}\left(\frac{\mathrm{I}+\mathrm{F}_{n}}{2}\right)^{\frac{1}{2}}$ & $\frac{\mathrm{I}+\mathrm{F}_{n}}{2}$ & $\frac{1+\mathrm{F}_{n}+2 \mathrm{~F}_{n+1}}{4}$ & $\frac{3+3 \mathrm{~F}_{n}+2 \mathrm{~F}_{n+1}}{8}$ & $\frac{5+5 \mathrm{~F}_{n}+6 \mathrm{~F}_{n+1}}{\mathrm{I} 6}$ \\
\hline
\end{tabular}

As in (i), ${ }_{n} \eta_{k}$ satisfies the difference equation

with

$$
{ }_{n} \eta_{k+2}=\frac{1}{2}\left({ }_{n} \eta_{k}+{ }_{n} \eta_{k+1}\right)
$$

$$
\begin{aligned}
& { }_{n} \eta_{1}=\left(\frac{\mathrm{I}+\mathrm{F}_{n}}{2}\right)^{\frac{1}{2}} \\
& { }_{n} \eta_{2}=\frac{\mathrm{I}+\mathrm{F}_{n}+2 \mathrm{~F}_{n+1}}{2} \times\left(\frac{\mathrm{I}+\mathrm{F}_{n}}{2}\right)^{-\frac{1}{2}}
\end{aligned}
$$

The general solution of (4.3.5) can be expressed as

$$
{ }_{n} \eta_{k}=\left[\left(\frac{\mathrm{I}+\mathrm{F}_{n}+\mathrm{F}_{n+1}}{3}\right)-\left(-\frac{1}{2}\right)^{k}\left(\frac{\mathrm{I}+\mathrm{F}_{n}-2 \mathrm{~F}_{n+1}}{3}\right)\right]\left(\frac{\mathrm{I}+\mathrm{F}_{n}}{2}\right)^{-\frac{1}{2}}
$$

For large $k$, we may write

$$
{ }_{n} \eta_{\infty}=\left(\frac{\mathrm{I}+\mathrm{F}_{n}+\mathrm{F}_{n+1}}{3}\right)\left(\frac{\mathrm{I}+\mathrm{F}_{n}}{2}\right)^{-\frac{1}{2}}
$$

(iv) Corr. $\left(\mathrm{X}_{n}, \mathrm{D}_{n+k}\right)$

Let

$$
\left.\begin{array}{l}
\mathrm{Q}_{11}^{\prime}=\operatorname{Prob}\left(\mathrm{X}_{n}=\mathrm{AA} ; \mathrm{D}_{n+k}=\mathrm{AA}\right) \\
\mathrm{Q}_{12}^{\prime}=\operatorname{Prob}\left(\mathrm{X}_{n}=\mathrm{A} a ; \mathrm{D}_{n+k}=\mathrm{AA}\right) \\
\mathbf{Q}_{21}^{\prime}=\operatorname{Prob}\left(\mathrm{X}_{n}=\mathrm{AA} ; \mathrm{D}_{n+k}=\mathrm{A} a\right) \\
\mathbf{Q}_{22}^{\prime}=\operatorname{Prob}\left(\mathrm{X}_{n}=\mathrm{A} a ; \mathrm{D}_{n+k}=\mathrm{A} a\right)
\end{array}\right\}
$$

Then,

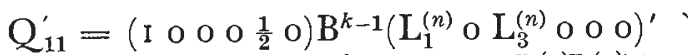

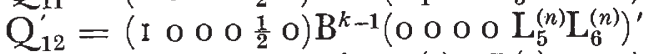

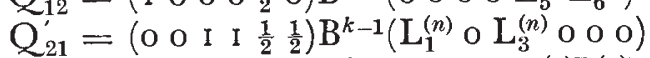

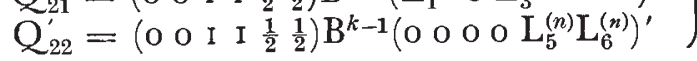


Hence

$$
\begin{aligned}
& Q_{11}^{\prime}+\frac{1}{2}\left(Q_{12}^{\prime}+Q_{21}^{\prime}\right)+\frac{1}{4} Q_{22}^{\prime} \\
&=\left(\text { I } \circ \frac{1}{2} \frac{1}{2} \frac{3}{4} \frac{1}{4}\right) B^{k-1}\left(L_{1}^{(n)} \circ L_{3}^{(n)} \circ \frac{L_{5}^{(n)}}{2} \frac{L_{6}^{(n)}}{2}\right)
\end{aligned}
$$

Then

$$
\operatorname{Cov}\left(\mathrm{X}_{n}, \mathrm{D}_{n+k}\right)=\left[\mathrm{Q}_{11}^{\prime}+\frac{1}{2}\left(\mathrm{Q}_{12}^{\prime}+\mathrm{Q}_{21}^{\prime}\right)+\frac{1}{4} \mathrm{Q}_{22}^{\prime}\right] y_{1}^{2}-p^{2} y_{1}^{2} \quad(4 \cdot 4 \cdot 4)
$$

Table 5 below gives the correlation coefficients for various values of $k$ :

TABLE 5

\begin{tabular}{|c|c|c|}
\hline$k$ & $\mathrm{I}$ \\
\hline$n_{n}^{\prime} \times\left(\frac{\mathrm{I}+\mathrm{F}_{n}}{2}\right)^{\frac{1}{2}}$ & $\frac{\mathrm{I}+\mathrm{F}_{n}+2 \mathrm{~F}_{n+1}}{4} \times\left(\frac{\mathrm{I}+\mathrm{F}_{n+1}}{2}\right)^{-\frac{1}{2}}$ & $\frac{3+3 \mathrm{~F}_{n}+2 \mathrm{~F}_{n+1}}{8} \times\left(\frac{\mathrm{I}+\mathrm{F}_{n+2}}{2}\right)^{-\frac{1}{2}}$ \\
\hline$k$ & 3 & 4 \\
\hline${ }_{n} \eta_{k}^{\prime} \times\left(\frac{\mathrm{I}+\mathrm{F}_{n}}{2}\right)^{\frac{1}{2}}$ & $\frac{5+5 \mathrm{~F}_{n}+6 \mathrm{~F}_{n+1} \times\left(\frac{\mathrm{I}+\mathrm{F}_{n+3}}{2}\right)^{-\frac{1}{2}}}{\frac{\mathrm{I}}{2}+\mathrm{IIF}_{n}+\mathrm{IOF}_{n+1} \times\left(\frac{\mathrm{I}+\mathrm{F}_{n+4}}{2}\right)^{-\frac{1}{2}}}$ \\
\hline
\end{tabular}

In general

$$
{ }_{n} \eta_{k}^{\prime}={ }_{n} \eta_{k+1}\left(\frac{\mathrm{I}+\mathrm{F}_{n+k}}{2}\right)^{-\frac{1}{2}}
$$

where ${ }_{n} \eta_{k+1}$ is given by $(4 \cdot 3.6)$ with $k$ replaced by $k+\mathrm{I}$. For large $k$, we have

as $\mathrm{F}_{n+k} \rightarrow \mathrm{I}$.

$$
\begin{aligned}
{ }_{n} \eta_{k}^{\prime} & \simeq{ }_{n} \eta_{k+1} \\
& \simeq{ }_{n} \eta_{k}
\end{aligned}
$$

\section{DISCUSSION}

It is noted that because of the particular initial conditions, the latent root $-\frac{1}{2}$ does not appear at all in any of the expressions.

The covariance between mother and daughter for a sex-linked case and that between parent-offspring for an autosomal case is found to be the same. This is to be expected, since the segregation in the female is the same either for sex-linked or autosomal characters.

It is interesting to note from section 4 that the limiting values of the correlations between an individual and his/her $k^{\text {th }}$ degree offspring do not depend on the sex of the offspring, the limiting value, as $k$ becomes larger, being the same. 


\section{SUMMARY}

In this paper expressions for correlations between parent-offspring and full-sib pairs are derived for a sex-linked character under full-sib mating system. General expressions for correlations between an individual and his/her offspring of the $k^{\text {th }}$ degree are also derived assuming no dominance. The results obtained are briefly discussed. The case of a single locus with two alleles affecting the sex-linked character alone is considered.

\section{REFERENCES}

FISHER, R. A. 1918. The correlation between relatives on the supposition of Mendelian inheritance. Trans. Roy. Soc. Edinb., 52, 399-433.

FISHER, R. A. I949. The Theory of Inbreeding. Oliver and Boyd, Edinburgh.

HALDANE, J. B. s. 1937. Some theoretical results of continued brother-sister mating. 7. Genet., 34, 265-274.

HALDANE, J. B. S. I955. The complete matrices for brother-sister and parentoffspring mating involving one locus. 7 . Genet., 53, 31 5-324.

HORNER, T. W. 1956. Parent-offspring and full-sib correlations under a parentoffspring mating system. Genetics, $4^{I}, 460-468$.

KEMPTHORNE, O. 1955. The correlations between relatives in inbred populations. Genetics, $40,68 \mathrm{I}-69 \mathrm{I}$.

kempthorne, o. 1957. An Introduction to Genetic Statistics. John Wiley and Sons. 